\title{
Selection of Marine Security Policy using Fuzzy-AHP TOPSIS Hybrid Approach
}

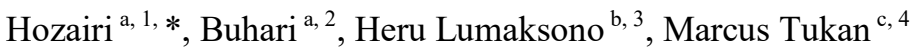 \\ ${ }^{a}$ Informatics Eng. Study Program, Islamic University of Madura \\ Jl.PP.Miftahul Ulum Bettet, Pamekasan 6931, Indonesia \\ ${ }^{b}$ Department of Shipbuilding Engineering, Shipbuilding Institute of Polytechnic Surabaya \\ Jl. Teknik Kimia ITS, Surabaya 60111, Indonesia \\ ${ }^{c}$ Faculty of Engineering, University of Pattimura \\ Jl. Ir M Putuhena, Ambon 97233, Indonesia \\ 1'dr.hozairi@gmail.com*; ${ }^{2}$ buharinahrawi@gmail.com; ${ }^{3}$ heruppns@gmail.com; ${ }^{4}$ marcustucan@gmail.com \\ * corresponding author
}

ARTICLE INFO

Article history:

Received 3 December 2019

Revised 24 January 2019

Accepted 22 April 2019

Published online 23 June 2019

Keywords:

Marine security policy

Global maritime axis

Fuzzy-AHP

TOPSIS

\section{ABSTRACT}

The research was focused on the integration of Fuzzy set theory with Analytic Hierarchy Process (AHP) and Technique for Order Preference by Similarity to Ideal Solution (TOPSIS) to choose the optimum maritime security policy to achieve Indonesia recognition as the world's maritime axis. The method used is AHP with fuzzy based enhancement. Here, the weight of each criterion is calculated to overcome the criticism of the scale of unbalanced rating, uncertainty, and inaccuracy in the pairwise of comparison process. The best recommendation for Indonesian maritime policies is multi task single agency which is greatly infuenced by several factors such as technology, regulations, infrastructure, economic, politic, and socio-culture. The finding shows that the hybrid approach is able to produce the best recommendation for Indonesian maritime security policy.

This is an open access article under the CC BY-SA license (https://creativecommons.org/licenses/by-sa/4.0/).

\section{Introduction}

Indonesia is an archipelago with an area of ocean exceeding mainland. Geographically, Indonesia is located between two continents and two oceans, and has a large wealth of natural resources. As an archipelagic country, Indonesia should also be called a maritime country. However, addressing Indonesia as a maritime country seems inappropriate because the development between the land and the sea is not balance [1][2].

For that reason, since 2014, Indonesia has focused on organising the maritime affairs for the nation's prosperity [3]. The Indonesian government through Presidential Regulation No. 178 of 2014, established a Marine Security Agency (Bakamla), which was previously named the Marine Security Coordination Agency (Bakorkamla) [4]. As consequence, the Indonesian Government is required to choose the right Indonesian maritime security policy so as to be able to realize the ideals of Indonesia as the World Maritime Axis [5][6]. Choosing an Indonesian maritime security policy is not easy because it has to consider many criteria. Therefore a Decision Support System (DSS) [7] is needed to recommend the most suitable maritime policies [8].

This study aims to select the Indonesian maritime security policy by considering many criteria in each decision alternative. The process of selecting Indonesia's marine security policy is not easy because it includes complex problems and cannot be solved by linear programming methods. This problem is a multi criteria problem, requires a DSS approach, namely Multi Criteria Decision Making (MCDM) to solve it. MCDM determines the best of many alternatives based on specific criteria. Criteria are usually available in the form of measurements, rules or standards, are used in decision making process [9][10][11]. 
Another major advantage of MCDM techniques is their ability to analyze quantitative and qualitative criteria simultaneously. Many techniques and methodologies are reported in the literature. Some popular approaches are Analytical Hierarchy Process (AHP) [12], Analytic Network Process (ANP), Technique for Preference by Ideal for Ideal Solution (TOPSIS) [13], Elimination and Choice Translation Reality (ELECTRE) [14][15], Preference Ranking for Organization Method for Enrichment Evaluation (PROMETHEE) [16], Decision making trial and evaluation laboratory (DEMATEL), and Vse Kriterijumska Optimizacija I Komprominsa Resenje (VIKOR). Each technique has its own strengths and weaknesses. Therefore, a hybrid technique could be a solution on improving the performance of these stand-alone approaches.

In this study, an integrated model of fuzzy-AHP and TOPSIS was established to provide a phased methodology for selecting Indonesia's maritime security policy in accordance with Presidential Regulation No. 178 of 2014. This model was then applied in case studies to demonstrate its application in real-world pilot studies and prove its reliability. Fuzzy-AHP has good ability to resolve uncertainties and ambiguities in various MCDM situations [13][17][18][19]. On the other hand, TOPSIS is a model that is efficient in handling reasonable attributes and there is no limit to the number of criteria, sub-criteria or alternatives [20][21][22]. Thus, Fuzzy-AHP and TOPSIS integration should provide a good basis for the analysis of complex decision problems [23][24][25][26]. The easy programmed hybrid technique is expected to overcome the complex problem of maritime decision making.

\section{Methods}

This study aims to analyse the Indonesian marine security model by considering many criteria on each decision alternative. Based on the purpose, MCDM can be divided into 2 (two) models: Multi Atribute Decision Making (MADM), Multi Objective Decision Making (MODM). Often MADM and MODM are used to solve multi-attribute and multi-objective problems. MCDM method developed in this research is Fuzzy AHP and TOPSIS. In general, the stages of this research process can be seen in Figure 1.

\section{A. Fuzzy AHP}

The use of AHP in the Multi Criteria Decision Making (MCDM) problem is often criticized in light of the inadequacy of this AHP approach to overcome the uncertain factor experienced by the decision maker when it must provide a definite value in a pairwise comparison matrix. Therefore, to overcome the weakness of existing AHP then developed a method called fuzzy AHP. AHP fuzzy method is a combination of AHP method with fuzzy approach.

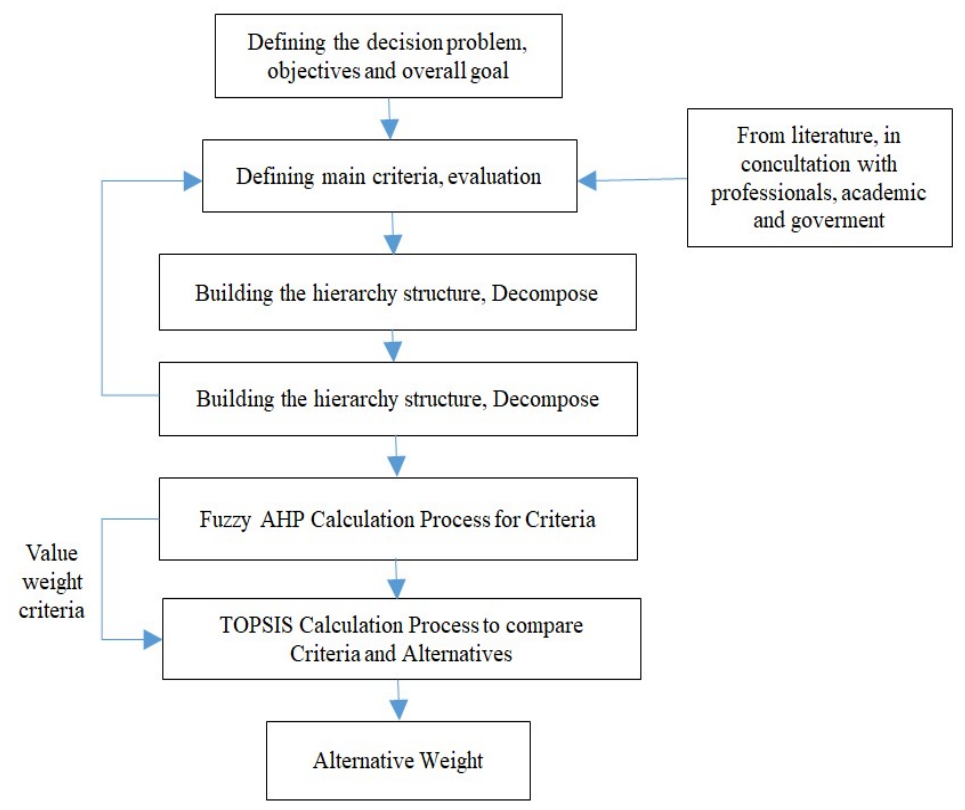

Fig. 1. The framework of fuzzy based AHP-TOPSIS multi criteria decision analysis 
The fuzzy AHP method uses Triangular Fuzzy Number (TFN). TFN is used to describe linguistic variables with certainty. TFN is symbolized by $M=(l, m, u)$ where $l$ is the lowest value, $m$ is the middle value, and $u$ is the top. The AHP and TFN ratings are used for purposes of the pairwise comparison matrix, as shown in Table 1.

If we suppose there are 2 (two) Triangular Fuzzy Number (TFN) that is $M_{l}=l_{1}, m_{1}, u_{1}$ and $M_{2}=$ $l_{2}, m_{2}, u_{2}$, then TFN arithmetic operation is:

$$
\begin{aligned}
& M_{1}+M_{2}=\left(l_{1}+l_{2}, m_{1}+m_{2}, u_{1}+u_{2}\right) \\
& M_{1} \otimes M_{2}=\left(l_{1} l_{2}, m_{1} m_{2}, u_{1} u_{2}\right) \\
& M_{1}^{-1}=\left(1 / u_{1}, 1 / m_{1}, 1 / l_{1}\right)
\end{aligned}
$$

Fuzzy Analytic Hierarcy Process (FAHP) stage are: defining the fuzzy synthetic extend value, confidence level, the level of probability for a convex fuzzy numbers, and normalization of weighted vector

\section{1) Fuzzy synthetic extend value}

Define the fuzzy synthetic extent value for i-objects like the following equation:

$$
S_{i}=\sum_{j=i}^{m} M_{g^{i}}^{j} \otimes\left[\sum_{i=1}^{n} \sum_{j=1}^{m} M_{g^{i}}^{j}\right]^{-1}
$$

To get $\sum_{j=1}^{m} M_{g^{i}}^{j}$, then a fuzzy sum operation is performed from the value of $m$ in a pairwise matrix of comparison as can be seen in the following equation:

$$
\sum_{j=1}^{m} M_{g^{i}}^{j}=\left(\sum_{j=1}^{m} l_{j}, \sum_{j=1}^{m} m_{j}, \sum_{j=1}^{m} u_{j}\right)
$$

To obtain equation (6):

$$
\left[\sum_{i=1}^{n} \sum_{j=1}^{m} M_{g^{i}}^{j}\right]
$$

Then summed on $M_{g^{i}}^{j}$ as can be seen in Equation (7):

$$
\left[\sum_{i=1}^{n} \sum_{j=1}^{m} M_{g^{i}}^{j}\right]=\left(\sum_{j=1}^{m} l_{j}, \sum_{j=1}^{m} m_{j}, \sum_{j=1}^{m} u_{j}\right)
$$

Then, to obtain the inverse of equation (7) can be done by using TFN arithmetic operation on Equation (3) which resulted in equation (8):

$$
\left[\sum_{i=1}^{n} \sum_{j=1}^{m} M_{g^{i}}^{j}\right]^{-1}=\left(\frac{1}{\sum_{j=1}^{m} l_{j}}, \frac{1}{\sum_{j=1}^{m} m_{j}}, \frac{1}{\sum_{j=1}^{m} u_{j}}\right)
$$

\section{2) Confidence level}

If there are two fuzzy numbers $M_{1}=\left(l_{1}, m_{1}, u_{1}\right)$ and $M_{2}=\left(l_{2}, m_{2}, u_{2}\right)$, then the confidence level of $M_{1}=\left(l_{1}, m_{1}, u_{1}\right) \geq M_{2}=\left(l_{2}, m_{2}, u_{2}\right)$ can be defined as follows:

$$
V\left(M_{1} \geq M_{2}\right)=\sup \left[\min \left(\mu M_{1}(x), \mu M_{2}(y)\right)\right]
$$

If $\mathrm{M}_{1}$ and $\mathrm{M}_{2}$ of the convex fuzzy number are obtained the following conditions:

$$
\begin{aligned}
& V\left(M_{1} \geq M_{2}\right)=1 \text { iff } m_{1} \geq m_{2} \\
& V\left(M_{1} \geq M_{2}\right)=\operatorname{hgt}\left(M_{1} \cap M_{2}\right)=\mu_{M_{1}}(d)
\end{aligned}
$$

Table 1. Triangular fuzzy scale of preference

\begin{tabular}{lll}
\hline Linguistic Term & AHP Scale & Triangular Fuzzy Number (TFN) \\
\hline Absolute & 9 & $(7,9,9)$ \\
Very Strong & 7 & $(5,7,9)$ \\
Fairly Strong & 5 & $(3,5,7)$ \\
Weak & 3 & $(1,3,5)$ \\
Equal & 1 & $(1,1,3)$ \\
\hline
\end{tabular}




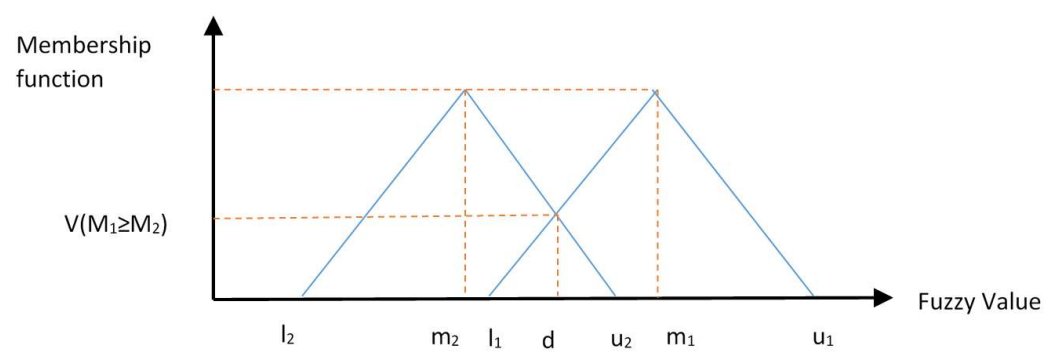

Fig. 2. The framework of fuzzy based AHP-TOPSIS multi criteria decision analysis

The confidence level of the fuzzy number can be obtained by the equation:

$$
V\left(M_{2} \geq M_{1}\right)=\left\{\begin{array}{c}
1, \text { if } m_{2} \geq m_{1} \\
0, \text { if } l_{1} \geq \mu_{2} \\
\frac{\left(l_{1}-u_{2}\right)}{\left(m_{2}-u_{2}\right)-\left(m_{1}-l_{1}\right)}, \text { otherwise }
\end{array}\right.
$$

Comparison of two fuzzy numbers can be seen in Figure 2 which shows that $d$ is the highest intersection point coordinate between $\mu_{M 1}$ and $\mu_{M 2}$, to compare $M_{1}=\left(l_{1}, m_{1}, u_{1}\right)$ and $M_{2}=\left(l_{2}, m_{2}, u_{2}\right)$ requires value from $V\left(M_{1} \geq M_{2}\right)$ and $V\left(M_{2} \geq M_{1}\right)$.

\section{3) Level of probability}

The level of probability for a convex fuzzy numbers better than than $\mathrm{k}$ convex fuzzy numbers $\mathrm{M}_{1}$ $(\mathrm{i}=1,2,3, \ldots, \mathrm{k})$ can be defined as follows:

$$
\begin{aligned}
V(M & \left.\geq M_{1}, M_{2}, \ldots \ldots, M_{k}\right) \\
& =V\left[\left(M \geq M_{1}\right) \text { and }\left(M \geq M_{2}\right) \text { and } \ldots\left(M \geq M_{k}\right)\right] \\
& =\min V\left(M \geq M_{i}\right), i=1,2, \ldots, k
\end{aligned}
$$

It is assumed that:

$$
d^{\prime}\left(A_{i}\right)=\min V\left(S_{i} \geq S_{k}\right)
$$

for $\mathrm{k}=1,2, \ldots, \mathrm{n} ; \mathrm{k} \neq \mathrm{I}$, then the weight of the vector is defined as follows:

$$
W^{\prime}=\left(d^{\prime}\left(A_{1}\right), d^{\prime}\left(A_{2}\right), \ldots, d^{\prime}\left(A_{n}\right)\right)^{T}
$$

\section{4) Normalization of weighted vector}

Normalization of weighted vector in equation (15) becomes:

$$
W=\left(d\left(A_{1}\right), d\left(A_{2}\right), \ldots, d\left(A_{n}\right)\right)^{T}
$$

where $W$ is not a fuzzy number.

\section{B. TOPSIS}

TOPSIS is one of the main MCDM techniques. This approach is based on the best alternative that has the closest distance from the positive ideal solution (PIS) and the farthest distance from the negative ideal solution (NIS). It has been widely applied in many fields of research related to the selection of various alternatives and risk analysis because of the rationality, logic and simplicity of the method.

To solve multi criteria problems with the TOPSIS method there are several steps that must be completed, namely:

Step 1 Normalise the decision matrix

$$
r_{i j}=\frac{w_{i j}}{\sqrt{\sum_{j}^{i} w_{i j}^{2}}}, j=1,1, \ldots . j ; i=1,2, \ldots ., n
$$


Step 2 Apply weight to the normalized decision matrix by multiplying the normalized matrix with the weights of the criteria:

$v_{i j}=w_{i} * r_{i j}=1,2, \ldots ., j ; i=1,2, \ldots, n$

Step 3 Determine both PIS (maximum values) and NIS (minimum values) as:

$$
\begin{aligned}
& A^{+}=\left\{v_{1}^{+}, v_{2}^{+}, \ldots \ldots, v_{n}^{+}\right\} \\
& A^{-}=\left\{v_{1}^{-}, v_{2}^{-}, \ldots \ldots, v_{n}^{-}\right\}
\end{aligned}
$$

Step 4 Calculate the distance of each alternative from PIS and NIS:

$$
\begin{aligned}
& D_{i}^{+}=\sqrt{\sum_{j=1}^{n}\left(v_{i j}-v_{j}^{+}\right)^{2}}, j=1,2, \ldots, j \\
& D_{i}^{-}=\sqrt{\sum_{j=1}^{n}\left(v_{i j}-v_{j}^{-}\right)^{2}}, j=1,2, \ldots, j
\end{aligned}
$$

Step 5 Calculate the closeness coefficient of each alternative (Ci) relative to its distance from PIS and NIS:

$$
C_{i}=\frac{D_{i}^{+}}{D_{i}^{+}+D_{i}^{-}}
$$

Step 6 Compare the $\mathrm{Ci}$ values to determine the ranking of alternatives.

This research begins by agreeing on the criteria that are considered in the selection of a suitable Indonesian maritime security policy which then later determine the alternatives that will be rated as Table 2.

The proposed approach consists of three steps. In the first stage, compiling the policy criteria is taken into consideration to determine the structured decision hierarchy. Decision hierarchy should be approved by the policy-making team with several considerations of internal factors and external factors. The next process assess the criteria using Fuzzy AHP. As explained in section 2, linguistic values are used to determine the weight criteria. In the third stage, the Indonesian maritime security policy model is ranked using the TOPSIS procedure. Ranking is based on $\mathrm{C}_{\mathrm{i}}$ values in the order of the high. The maximum $C_{i}$ value are selected as the best policy model. The schematic diagram of the proposed model is showed in in Figure 3.

\section{Results and Discussions}

The integrated maritime security policy requires the involvement of many actors in decision making such as the state sector and the civil sector. The concept of the World Maritime Axis is the concept of Maritime Security itself with prominent characteristics and focuses on several aspects: national, economic, environmental, and human security.

Table 2. Maritime security policy

\begin{tabular}{cl}
\hline Code & Description \\
\hline \multicolumn{2}{l}{ Security policy code } \\
C1 & Politics \\
C2 & Economics \\
C3 & Social-culture \\
C4 & Technology \\
C5 & Infrastructure \\
C6 & Regulation \\
Alternatif security policy code \\
A1 & Multy Agency Single Task \\
A2 & Multy Agency Multy Task \\
A3 & Single Agency Multy Task \\
A4 & Single Agency Single Task \\
\hline
\end{tabular}




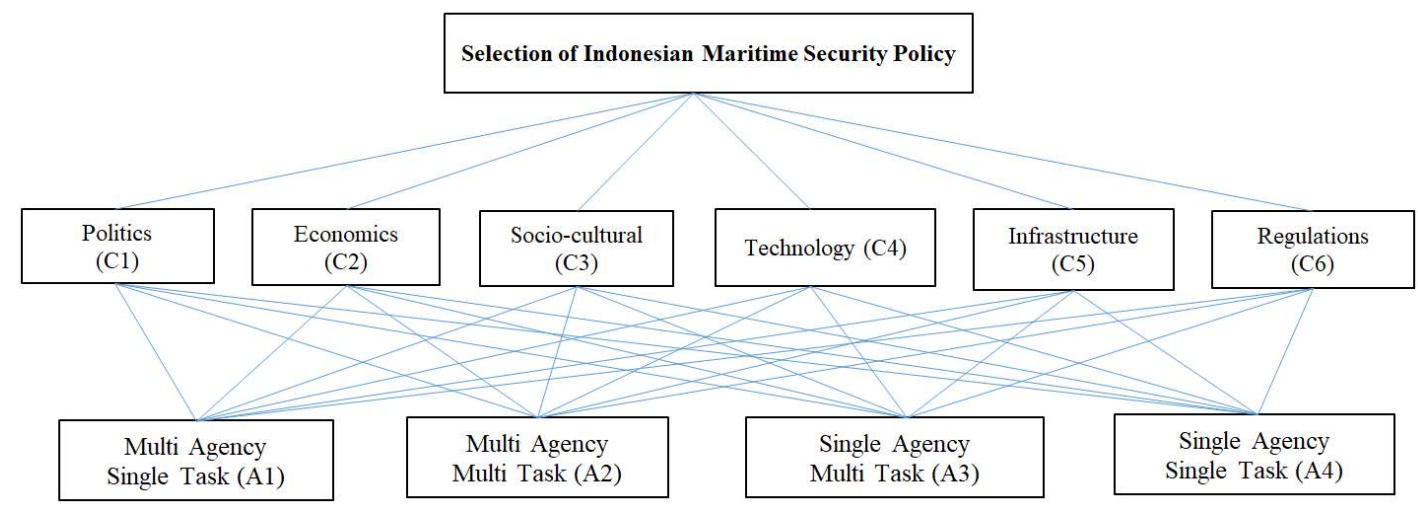

Fig. 3. Hierarchy of selection of Indonesian maritime security policies

Indonesia has twelve law enforcement agencies in the sea, of the twelve there are six institutions that have patrol boats as law enforcement tools at sea by conducting patrols at sea, namely: the Navy, Indonesian National Police, Ministry of Defense, Ministry of Maritime Affairs and Fisheries, Ministry of Transportation and Customs and Excise. There are six other marine law enforcement agencies that do not have patrol boats, namely: Ministry of Foreign Affairs, Ministry of Home Affairs, Ministry of Law and Human Rights, Attorney General's Office, Ministry of Finance and State Intelligence Agency.

Therefore, the proposed method analyzes the situation and simplify the decision-making process. For this purpose, a team of ten: Indonesian Ocean Security Agency, Navy, Indonesian National Police, Ministry of Defense, Ministry of Maritime Affairs and Fisheries, Ministry of Transportation, Customs and Excise, and author were formed. The experiences and perspectives of these members are used throughout the entire study by following the described procedures.

\section{A. Identification of criteria}

Important criteria for comparison of the Indonesian marine security policy model are determined by a team of experts based on their background and experience. The team agreed that the problem has six important criteria as shown in Figure 3.

The next step is creating a comparison between criteria to determine the most important criteria. The assessment process between criteria uses the Fuzzy AHP approach. The comparison scheme between criteria can be seen in Table 3. Decision hierarchy includes three levels: The overall objective "selection Indonesian maritime security policy" as the first level of the hierarchy, the criteria are on the second level and third level as the alternative.

\section{B. Weight criteria and alternatives}

The calculation of the fuzzy synthesis value leads to estimate the overall value of each desired criterion and alternative as presented in Table 3. Afterwards, the matrix elements in Table 3 is divided by the values in the row. The next stage sums the each line values, then divided it by the number of criteria to look for the Eigen Vector or the weight of each criterion. The calculation results can be seen in Table 4.

Table 3. The pairwise comparison matrix for criteria

\begin{tabular}{|c|c|c|c|c|c|c|c|c|c|c|c|c|c|c|c|c|c|c|}
\hline \multirow{2}{*}{ Criteria } & \multicolumn{3}{|c|}{ C1 } & \multicolumn{3}{|c|}{$\mathrm{C2}$} & \multicolumn{3}{|c|}{$\mathrm{C3}$} & \multicolumn{3}{|c|}{$\mathrm{C4}$} & \multicolumn{3}{|c|}{$\mathrm{C5}$} & \multicolumn{3}{|c|}{ C6 } \\
\hline & $\mathbf{L}$ & M & $\mathbf{U}$ & $\mathbf{L}$ & $\mathbf{M}$ & $\mathbf{U}$ & $\mathbf{L}$ & M & $\mathbf{U}$ & $\mathbf{L}$ & M & $\mathbf{U}$ & $\mathbf{L}$ & M & $\mathbf{U}$ & $\mathbf{L}$ & M & $\mathbf{U}$ \\
\hline $\mathrm{C} 1$ & 1.00 & 1.00 & 3.00 & 1.00 & 0.33 & 0.20 & 3.00 & 5.00 & 7.00 & 0.20 & 0.14 & 0.11 & 1.00 & 0.33 & 0.20 & 0.33 & 0.20 & 0.14 \\
\hline $\mathrm{C} 2$ & 1.00 & 3.00 & 5.00 & 1.00 & 1.00 & 3.00 & 3.00 & 5.00 & 7.00 & 0.33 & 0.20 & 0.14 & 1.00 & 1.00 & 3.00 & 1.00 & 0.33 & 0.20 \\
\hline $\mathrm{C} 3$ & 0.33 & 0.20 & 0.14 & 0.33 & 0.20 & 0.14 & 1.00 & 1.00 & 3.00 & 0.20 & 0.14 & 0.11 & 0.33 & 0.20 & 0.14 & 0.20 & 0.14 & 0.11 \\
\hline $\mathrm{C} 4$ & 5.00 & 7.00 & 9.00 & 3.00 & 5.00 & 7.00 & 5.00 & 7.00 & 9.00 & 1.00 & 1.00 & 3.00 & 5.00 & 7.00 & 9.00 & 1.00 & 3.00 & 5.00 \\
\hline $\mathrm{C} 5$ & 1.00 & 3.00 & 5.00 & 1.00 & 1.00 & 0.33 & 3.00 & 5.00 & 7.00 & 0.20 & 0.14 & 0.11 & 1.00 & 1.00 & 3.00 & 1.00 & 0.33 & 0.20 \\
\hline $\mathrm{C} 6$ & 3.00 & 5.00 & 7.00 & 1.00 & 3.00 & 5.00 & 5.00 & 7.00 & 9.00 & 1.00 & 0.33 & 0.20 & 1.00 & 3.00 & 5.00 & 1.00 & 1.00 & 3.00 \\
\hline
\end{tabular}


Table 4. Results calculation of the number of rows. number of columns and inverse values

\begin{tabular}{lllllllrl}
\hline \multirow{2}{*}{$\begin{array}{l}\text { TFN } \\
\text { (M) }\end{array}$} & \multicolumn{9}{c}{ Number of Rows } & \multicolumn{2}{c}{$\begin{array}{c}\text { Number of } \\
\text { columns }\end{array}$} & Inverse \\
\cline { 2 - 6 } & $\mathbf{C 1}$ & $\mathbf{C 2}$ & $\mathbf{C 3}$ & $\mathbf{C 4}$ & $\mathbf{C 5}$ & $\mathbf{C 6}$ & & \\
\hline $\mathrm{L}$ & 6.53 & 7.33 & 2.4 & 20 & 7.2 & 12 & 55.47 & 0.01 \\
$\mathrm{M}$ & 7.01 & 10.53 & 1.89 & 30 & 10.48 & 19.33 & 79.24 & 0.01 \\
$\mathrm{U}$ & 10.65 & 18.34 & 3.65 & 42 & 15.64 & 29.20 & 119.49 & 0.02 \\
\hline
\end{tabular}

Table 5. Results of fuzzy synthesis calculations ( $\mathrm{Si})$

\begin{tabular}{ccccc}
\hline \multirow{2}{*}{ Criteria } & \multicolumn{3}{c}{$\mathbf{S i}$} & $\mathbf{U}$ \\
\cline { 2 - 4 } & $\mathbf{L}$ & $\mathbf{M}$ & 0.19 \\
C1 & 0.05 & 0.09 & 0.33 \\
C2 & 0.06 & 0.13 & 0.07 \\
C3 & 0.02 & 0.02 & 0.76 \\
C4 & 0.17 & 0.38 & 0.28 \\
C5 & 0.06 & 0.13 & 0.53 \\
C6 & 0.10 & 0.24 & \\
\hline
\end{tabular}

After the value of the number of rows and columns is obtained, the value of fuzzy synthesis of each criterion $\left(\mathrm{S}_{\mathrm{Ki}}\right)$ with $\mathrm{i}=1,2, \ldots 4$ is calculated as follow

$$
\begin{array}{ll}
\mathrm{S}_{\mathrm{Ki}}=(\text { Number of rows }(\mathrm{L}, \mathrm{M}, \mathrm{U}) \text { * Invers }(\mathrm{L}, \mathrm{M}, \mathrm{U})) & \\
\mathrm{S}_{\mathrm{K} 1}=((6.53,7.01,10.65) * \text { Invers }(0.01,0.01,0.02)) & =(0.05,0.09,0.19) \\
\mathrm{S}_{\mathrm{K} 2}=((7.33,10.53,18.34) * \text { Invers }(0.01,0.01,0.02)) & =(0.06,0.13,0.33) \\
\mathrm{S}_{\mathrm{K} 3}=((2.40,1.89,3.65) * \text { Invers }(0.01,0.01,0.02)) & =(0.02,0.02,0.33) \\
\mathrm{S}_{\mathrm{K} 4}=((20.00,30.00,42.00) * \text { Invers }(0.01,0.01,0.02)) & =(0.17,0.38,0.76) \\
\mathrm{S}_{\mathrm{K} 5}=((7.20,10.48,15.64) * \text { Invers }(0.01,0.01,0.02)) & =(0.06,0.13,0.28) \\
\mathrm{S}_{\mathrm{K} 6}=((3.73,2.15,1.77) * \text { Invers }(0.01,0.01,0.02)) & =(0.04,0.03,0.03)
\end{array}
$$

The calculation of fuzzy synthesis values can be summarised in Table 5.

Determination of vector value $(\mathrm{V})$ and ordinate value of defuzification uses a fuzzy approach. It is the minimum implication (min) fuzzy function. Afterwards, we will get the ordinate value of defuzification (d') which is the minimum d value. Based on Table 5 , the values of vectors and ordinate defective values of each criterion are obtained. For instance, the first criteria is Politic $\left(\mathrm{K}_{1}\right)$, the value of vector is:

$\left(\mathrm{VK}_{1}\right) \geq\left(\mathrm{VK}_{2}, \mathrm{VK}_{3}, \mathrm{VK}_{4}, \mathrm{VK}_{5}, \mathrm{VK}_{6}\right)$

Because of the value $\mathrm{m} 1 \geq \mathrm{m} 2$ and $\mathrm{u} 2 \geq 11$ then $\mathrm{VK}_{1} \geq \mathrm{VK}_{2}$ :

$\mathrm{VK}_{1} \geq \mathrm{VK}_{2}=0.86$

$\mathrm{VK}_{1} \geq \mathrm{VK}_{3}=1$

$\mathrm{VK}_{1} \geq \mathrm{VK}_{4}=0.67$

$\mathrm{VK}_{1} \geq \mathrm{VK}_{5}=0.83$

$\mathrm{VK}_{1} \geq \mathrm{VK}_{6}=0.73$

Afterwards, the next stage obtained value d' $\left(\mathrm{VK}_{1}\right)$. Once finished, the calculation is repeated for the other criteria.

$$
\begin{aligned}
& d^{\prime}\left(V_{1}\right)=\min (0.86,1,0.67,0.83,0.73) \\
& d^{\prime}\left(V_{1}\right)=0.67
\end{aligned}
$$


Based on the ordinate values $\mathrm{K}_{1}, \mathrm{~K}_{2}, \mathrm{~K}_{3}, \mathrm{~K}_{4}, \mathrm{~K}_{5}$ and $\mathrm{K}_{6}$, then the value of the vector weight can be determined as follow:

Number of Vectors $=(0.67+0.71+0.62+1+0.71+0.81)=3.52$

As a result, the value of the vector weight in the first criterion is obtained.

$\mathrm{VK}_{1}=0.67 / 3.52=0.19$

The calculation result of other criteria is also presented in Table 6.

Finally, the total value of the vector weights in each criterion is summed

$\mathrm{W}=\left(\mathrm{VK}_{1}+\mathrm{VK}_{2}+\mathrm{VK}_{3}+\mathrm{VK}_{4}+\mathrm{VK}_{5}+\mathrm{VK}_{6}\right)$

Thus,

$\mathrm{W}=(0.19+0.20+0.18+0.28+0.20+0.23)=1.28$.

Normalize the value of the vector weight for the first criterion is

$\mathrm{WK}_{1}=0.19 / 1.28=0.15$

Third column of Table 6 shows the calculation result of the other criteria.

The results of the calculation of criteria weights using the Fuzzy AHP method obtained the following values of weighting: Politics $=0.15$; Economy $=0.16$; Social and Cultural $=0.14$; Technology $=0.22$; Infrastructure $=0.16$; and Policy $=0.18$. Here, the most influential factor is technology.

The next stage spreads questionnaires to several respondents (Ministry of Maritime Affairs and Fisheries, Indonesian Navy, Ministry of Defense, Ministry of Transportation, Police and Academics) who understand and have the authority of Indonesian maritime security policies. The questionnaire is

Table 6. The calculation result of weight of each criterion

\begin{tabular}{llll}
\hline Criteria & D'(VK) & VK & WK \\
\hline 1 & 0.67 & 0.19 & 0.15 \\
2 & 0.71 & 0.2 & 0.16 \\
3 & 0.62 & 0.18 & 0.14 \\
4 & 1 & 0.28 & 0.22 \\
5 & 0.71 & 0.2 & 0.16 \\
6 & 0.81 & 0.23 & 0.18 \\
\hline Total & 3.52 & 1.28 & \\
\hline
\end{tabular}

Table 7. Questionnaire value

\begin{tabular}{lll}
\hline Variables & Code & Value \\
\hline Very Poor & VP & 1 \\
Poor & P & 2 \\
Fair & F & 3 \\
Good & G & 4 \\
Very Good & VG & 5 \\
\hline
\end{tabular}

Table 8. Recapitulation of questionnaire results between criteria and decision alternative

\begin{tabular}{lllllll}
\hline Alternative & C1 & C2 & C3 & C4 & C5 & C6 \\
\hline A1 & 4.00 & 3.00 & 4.00 & 4.00 & 4.00 & 4.00 \\
A2 & 3.00 & 2.00 & 3.00 & 2.00 & 4.00 & 2.00 \\
A3 & 5.00 & 4.00 & 4.00 & 5.00 & 4.00 & 5.00 \\
A4 & 2.00 & 5.00 & 3.00 & 4.00 & 4.00 & 3.00 \\
\hline Average & 3.50 & 3.50 & 3.50 & 3.75 & 4.00 & 3.50 \\
\hline
\end{tabular}


used to assess the consistency of each alternative as detailed in Table 7. About 100 people fill the questionnaire. The result of the questionnaire recapitulation is shown in Table 8.

After obtained the comparative value of criteria and alternatives, the next step is looking for the value of squares and the roots of the assessment results using TOPSIS. Table 9 captures the calculation result. The process is followed by the multiplication of every element in Table 8 with its root in Table 9 to get a TOPSIS normalization matrix in Table 10.

The next step is to get a weighted normalization matrix by multiplying the TOPSIS normalization matrix with the weighted matrix of criteria (Table 6). The result is a weighted normalization matrix of TOPSIS with the Fuzzy-AHP can be seen in Table 11.

Table 9. Result of calculation Value of squares and roots

\begin{tabular}{lllllll}
\hline Criteria & C1 & C2 & C3 & C4 & C5 & C6 \\
\hline Square & 54.00 & 54.00 & 50.00 & 61.00 & 64.00 & 54.00 \\
Root & 7.35 & 7.35 & 7.07 & 7.81 & 8.00 & 7.35 \\
\hline
\end{tabular}

Table 10. Normalization Matrix

\begin{tabular}{lllllll}
\hline Alternative & C1 & C2 & C3 & C4 & C5 & C6 \\
\hline A1 & 0.54 & 0.41 & 0.57 & 0.51 & 0.50 & 0.54 \\
A2 & 0.41 & 0.27 & 0.42 & 0.26 & 0.50 & 0.27 \\
A3 & 0.68 & 0.54 & 0.57 & 0.64 & 0.50 & 0.68 \\
A4 & 0.27 & 0.68 & 0.42 & 0.51 & 0.50 & 0.41 \\
\hline
\end{tabular}

Table 11. The weighted normalization matrix

\begin{tabular}{lllllll}
\hline Alternative & C1 & C2 & C3 & C4 & C5 & C6 \\
\hline A1 & 0.081 & 0.064 & 0.078 & 0.071 & 0.078 & 0.098 \\
A2 & 0.061 & 0.043 & 0.059 & 0.035 & 0.078 & 0.049 \\
A3 & 0.101 & 0.085 & 0.078 & 0.088 & 0.078 & 0.123 \\
A4 & 0.040 & 0.106 & 0.059 & 0.071 & 0.078 & 0.074 \\
\hline
\end{tabular}

Table 12. The value of alternative distance of positive and negative solution

\begin{tabular}{lllllll}
\hline Value & C1 & C2 & C3 & C4 & C5 & C6 \\
\hline Maximum & 0.101 & 0.106 & 0.078 & 0.088 & 0.078 & 0.123 \\
Minimum & 0.040 & 0.043 & 0.059 & 0.035 & 0.078 & 0.049 \\
\hline
\end{tabular}

Table 13. Quadratic value of alternatives

\begin{tabular}{lll}
\hline Square Value & Benefit & Cost \\
\hline A1 & 0.003 & 0.006 \\
A2 & 0.014 & 0.000 \\
A3 & 0.000 & 0.014 \\
A4 & 0.007 & 0.006 \\
\hline
\end{tabular}

Table 14. Root values on alternatives

\begin{tabular}{lll}
\hline Root Value & Benefit & Cost \\
\hline A1 & 0.056 & 0.078 \\
A2 & 0.120 & 0.020 \\
A3 & 0.021 & 0.119 \\
A4 & 0.082 & 0.077 \\
\hline
\end{tabular}


The next step is finding the value of positive solution and negative solution and determining the distance between values, as showed in Table 12. The next stage, determines the square and root values of positive ideal values (PIS) and negative ideal values (NIS) which is presented in Table 13 and Table 14 respectively.

After obtaining the square and root values of PIS and NIS. Then the last step in the TOPSIS calculation is to find the preference value for each given alternative. If a larger $\mathrm{V}_{i}$ value indicates that the alternative $A_{i}$ is preferred. The preference values of each alternative are obtained as follows:

The preference value of Multy Agency Single Task Model

$$
V_{A 1}=\frac{0.078}{0.056+0.078}=0.583
$$

The preference value of Multy Agency Multy Task Model

$$
V_{A 2}=\frac{0.020}{0.120+0.020}=0.144
$$

The preference value of Single Agency Multy Task Model

$$
V_{A 3}=\frac{0.119}{0.021+0.119}=0.483
$$

The preference value of Single Agency Single Task Model

$$
V_{A 4}=\frac{0.077}{0.082+0.077}=0.848
$$

Having obtained the priority value on each alternative, then carried out the process of normalization of the decision value, shown in Table 15.

Based on the analysis of the interests of some concepts of marine security, it turns out the most suitable concept to be implemented in the State of Indonesia. First is the concept of Single Agency Multy Task, where all policies in handling law enforcement at sea are in one institution. Second is the Multy Agency Single Task, where there are more than one institution that interacts together to achieve or to solve similar problems. The third is Single Agency Single Task, where there is one institution that regulates and implements the regulations. This alternative is not possible to be applied because Indonesia already has many institutions with maritime authority of security. Fourth is Multy Agency Multy Task, where there are many institutions that have the duty and authority of oversight and marine security. The last concept has many weaknesses, especially the inter-agency sectoral ego.

Table 15. Priority value of alternative selection of Indonesian marine security concept

\begin{tabular}{lll}
\hline Alternative & Priority Value & Normalize Priority Values \\
\hline A1 & 0.583 & 0.283 \\
A2 & 0.144 & 0.070 \\
A3 & 0.848 & 0.412 \\
A4 & 0.483 & 0.235 \\
\hline
\end{tabular}

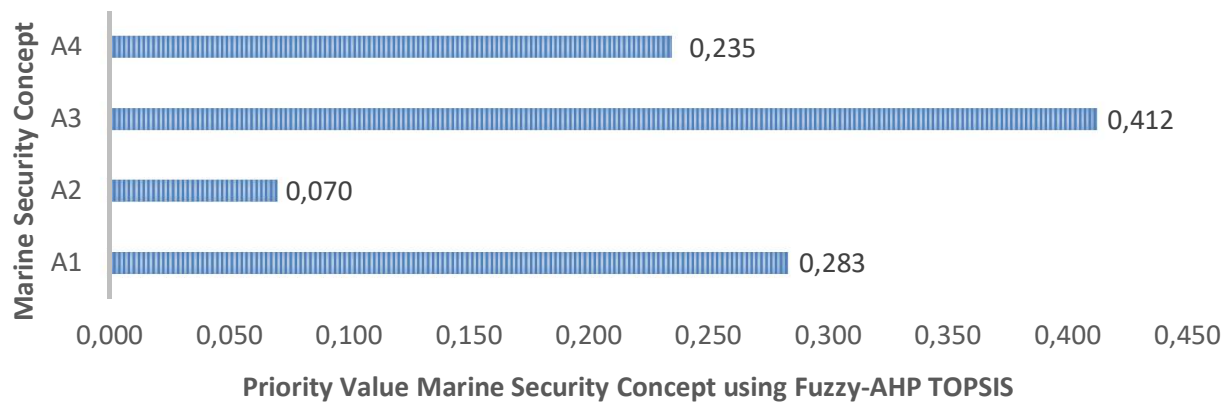

Fig. 4. Results of priority model of marine security Indonesia 
Figure 4 illustrates that the concept of "Single Agency Multy Tasks" has greatest contribution on addressing marine security and security enforcement issues in Indonesia. In contrast, other concepts may difficult to implement and may cause some problems such as overlapping authority, conflicts between law enforcement officers, and the absence of command and control units at the sea. The implementation of the Single Agency Multy Tasks system in Indonesia, can be done by optimizing the the synergy between authority, strength and ability of stakeholders.

\section{Conclusions}

In this paper, using Fuzzy AHP and TOPSIS, an integrated two-step model was established to evaluate in choosing the optimal maritime security policy to realize Indonesia as the world's maritime axis. Evaluation is based on several criteria, namely: politics, economy, social and culture, technology, infrastructure and policy. The Fuzzy-AHP found that the best criteria that greatly affect the improvement of marine security is technology, is followed by regulations, infrastructure, economic, politic, and socio-culture. The order of priority decisions of Indonesian maritime security policies based on TOPSIS are Multy Task Single Agency (0.412), Single Task Multy Agency (0.283), Single Task Single Agency (0.235), and Multy Multy Agency Task (0.070). The best recommendation for Indonesia marine security policy is "Multy Task Single Agency". The concept is believed to make a major contribution in overcoming various problems in the enforcement of security and safety laws at Indonesian sea. The concept requires a single institution to give one command, related to maritime security policy.

\section{Acknowledgment}

This research is supported by the Ministry of Research, Technology and Higher Education of the Republic of Indonesia through the National Strategic Research Grant.

\section{References}

[1] I. N. P. A, A. Hakim, S. H. Pramono, and A. S. Leksono, "The Effect of Strategic Environment Change toward Indonesia Maritime Security: Threat and Opportunity,” Int. J. Appl. Eng. Res., vol. 12, no. 16, pp. 6037-6044, 2017.

[2] A. P. Lis Gindarsah, "Indonesia’s Maritime Doctrine and Security Concerns,” 2014.

[3] I. Chapsos and J. A. Malcolm, "Maritime security in Indonesia : Towards a comprehensive agenda?," Mar. Policy, vol. 76, no. April 2016, pp. 178-184, 2017.

[4] G. Wasito, "The authority of BAKAMLA in the enforcement of certain criminal acts at sea is based on Law No. 32 of 2014 concerning maritime affairs," 2015.

[5] U. Muawanah et al., "Review of national laws and regulation in Indonesia in relation to an ecosystem approach to fisheries management," Mar. Policy, vol. 91, no. August 2017, pp. 150-160, 2018.

[6] A. H. I Nengah Putra A, "Analyze opportunities and threats of Indonesian maritime security as a result of the development of a strategic environment," 2016.

[7] M. Ilangkumaran and S. Kumanan, "Selection of maintenance policy for textile industry using hybrid multi-criteria decision making approach,” J. Manuf. Technol. Manag., vol. 20, no. 7, pp. 1009-1022, 2009.

[8] C. Bueger, "What is maritime security?," Mar. Policy, vol. 53, pp. 159-164, 2015.

[9] S. A. Ghassemi and S. Danesh, "A hybrid fuzzy multi-criteria decision making approach for desalination process selection," Desalination, vol. 313, pp. 44-50, 2013.

[10] H. Lumaksono, "The selection of suitable fishing gear for fishermen in Madura Island using Fuzzy AHP and Fuzzy TOPSIS," Ecoterra, vol. 15, no. 2, pp. 34-51, 2018.

[11] O. Gottfried et al., "SWOT-AHP-TOWS analysis of private investment behavior in the Chinese biogas sector," J. Clean. Prod., 2018.

[12] L. a. Zadeh, "Fuzzy sets," Inf. Control, vol. 8, no. 3, pp. 338-353, 1965.

[13] S. H. Zyoud et al., "A framework for water loss management in developing countries under fuzzy environment: Integration of Fuzzy AHP with Fuzzy TOPSIS,” Expert Syst. Appl., vol. 36, no. 1, pp. 61-67, 2012.

[14] X. Yu, S. Zhang, X. Liao, and X. Qi, "ELECTRE methods in prioritized MCDM environment," Inf. Sci. (Ny)., vol. 424, pp. 301-316, 2018.

[15] A. Zandi and E. Roghanian, "Extension of Fuzzy ELECTRE based on VIKOR method,” Comput. Ind. Eng., vol. 66, no. 2, pp. 258-263, 2013.

[16] S. Corrente, S. Greco, and R. SŁowiński, "Multiple Criteria Hierarchy Process with ELECTRE and PROMETHEE," Omega (United Kingdom), vol. 41, no. 5, pp. 820-846, 2013.

[17] A. Loganathan and I. Mani, "A fuzzy based hybrid multi criteria decision making methodology for phase change material selection in electronics cooling system," Ain Shams Eng. J., vol. 9, no. 4, pp. 2943-2950, 2018. 
[18] S. Dožić, T. Lutovac, and M. Kalic, "Fuzzy AHP approach to passenger aircraft type selection," J. Air Transp. Manag., vol. 68, pp. 165-175, 2018.

[19] D.-Y. Chang, "Applications of the extent analysis method on fuzzy AHP," Eur. J. Oper. Res., vol. 95, no. 3, pp. 649655, 1996.

[20] P. Sirisawat and T. Kiatcharoenpol, "Fuzzy AHP-TOPSIS approaches to prioritizing solutions for reverse logistics barriers," Comput. Ind. Eng., vol. 117, no. April 2017, pp. 303-318, 2018.

[21] T. Kaya and C. Kahraman, "Multicriteria decision making in energy planning using a modified fuzzy TOPSIS methodology," Expert Syst. Appl., vol. 38, no. 6, pp. 6577-6585, 2011.

[22] Y. K. Hozairi, "Decision Support System Determination of Main Work Unit in WPP-711 using Fuzzy TOPSIS," Knowl. Eng. Data Sci., vol. 1, no. 1, pp. 8-19, 2018.

[23] M. S. Problem, "Combined Fuzzy AHP and TOPSIS Method for Solvinglocation Problem,” vol. 8, pp. 373-383, 2006.

[24] A. T. Gumus, "Evaluation of hazardous waste transportation firms by using a two step fuzzy-AHP and TOPSIS methodology," Expert Syst. Appl., vol. 36, no. 2, pp. 4067-4074, 2009.

[25] G. Büyüközkan and G. Çifçi, “A combined fuzzy AHP and fuzzy TOPSIS based strategic analysis of electronic service quality in healthcare industry," Expert Syst. Appl., vol. 39, pp. 2341-2354, 2012.

[26] R. K. Shukla, D. Garg, and A. Agarwal, "An integrated approach of Fuzzy AHP and Fuzzy TOPSIS in modeling supply chain coordination," Prod. Manuf. Res., vol. 2, no. 1, pp. 415-438, 2014. 